\title{
Supporting information for: Hydrogen-assisted defect engineering of doped poly-Si films for passivating contact solar cells
}

Thien N. Truong, ${ }^{1, *}$ Di Yan, ${ }^{1}$ Christian Samundsett, ${ }^{1}$ Anyao Liu, ${ }^{1}$ Steven P. Harvey, ${ }^{2}$ Matthew Young, ${ }^{2}$ Zetao Ding, ${ }^{1}$ Mike Tebyetekerwa, ${ }^{1}$ Felipe Kremer, ${ }^{3}$ Mowafak Al-Jassim, ${ }^{2}$ Andres Cuevas, ${ }^{1}$ Daniel Macdonald, ${ }^{1}$ Hieu T. Nguyen ${ }^{1,}{ }^{*}$

${ }^{1}$ Research School of Electrical, Energy and Materials Engineering, College of Engineering and Computer Science, The Australian National University, Canberra, ACT 2601, Australia

2 National Renewable Energy Laboratory, Golden, Colorado 80401, United States

${ }^{3}$ Centre for Advanced Microscopy, The Australian National University, Canberra, ACT 2601, Australia

*Corresponding emails:

TT: thien.truong@anu.edu.au

HN: hieu.nguyen@anu.edu.au 

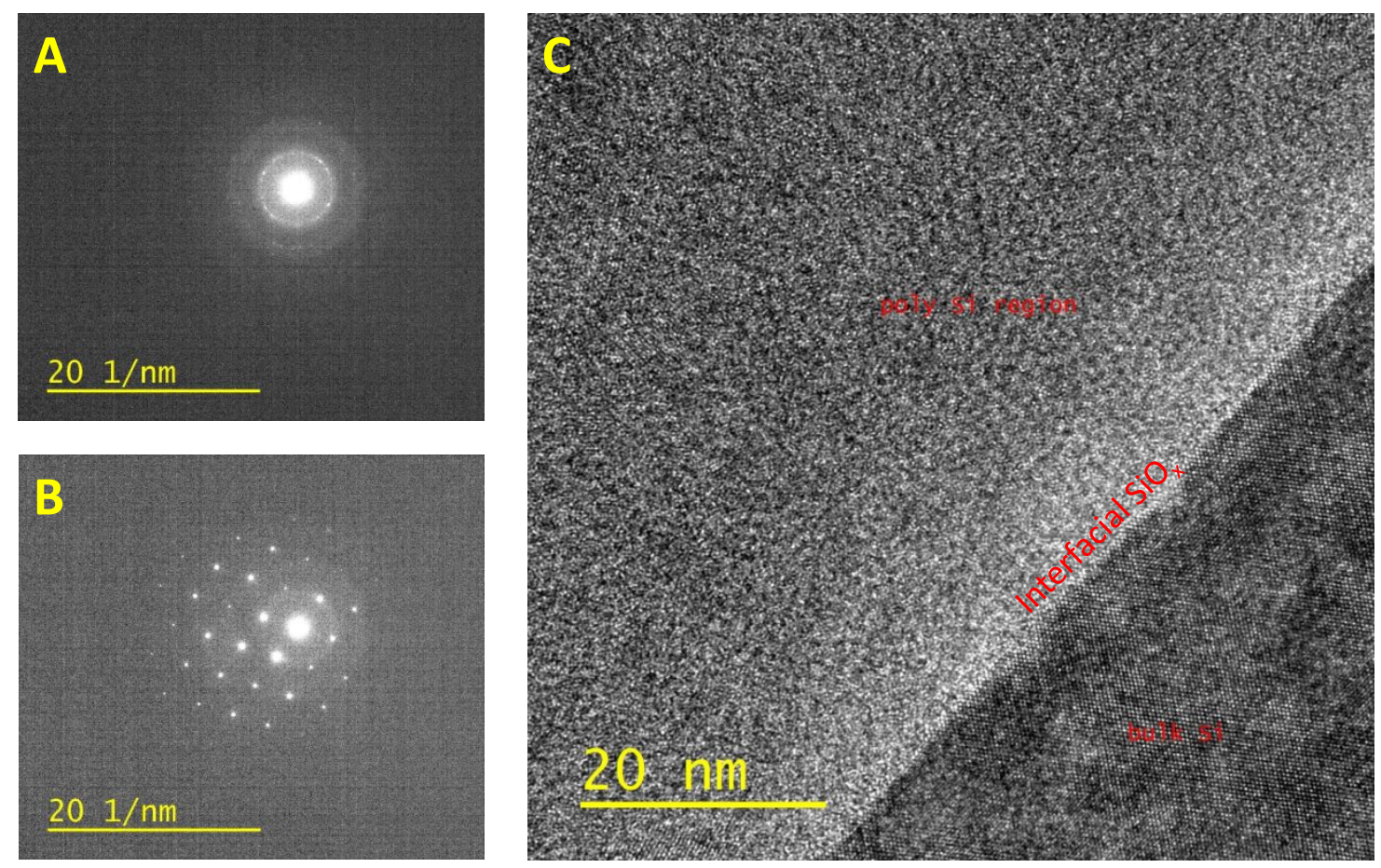

Figure S1. (A) Diffraction pattern from the boron-doped poly-Si layer. (B) Diffraction pattern from the c-Si substrate. (C) High-resolution TEM image of a selected area of the boron-doped poly-Si/SiO $/ \mathrm{c}-\mathrm{Si}$ structure on a planar substrate. 

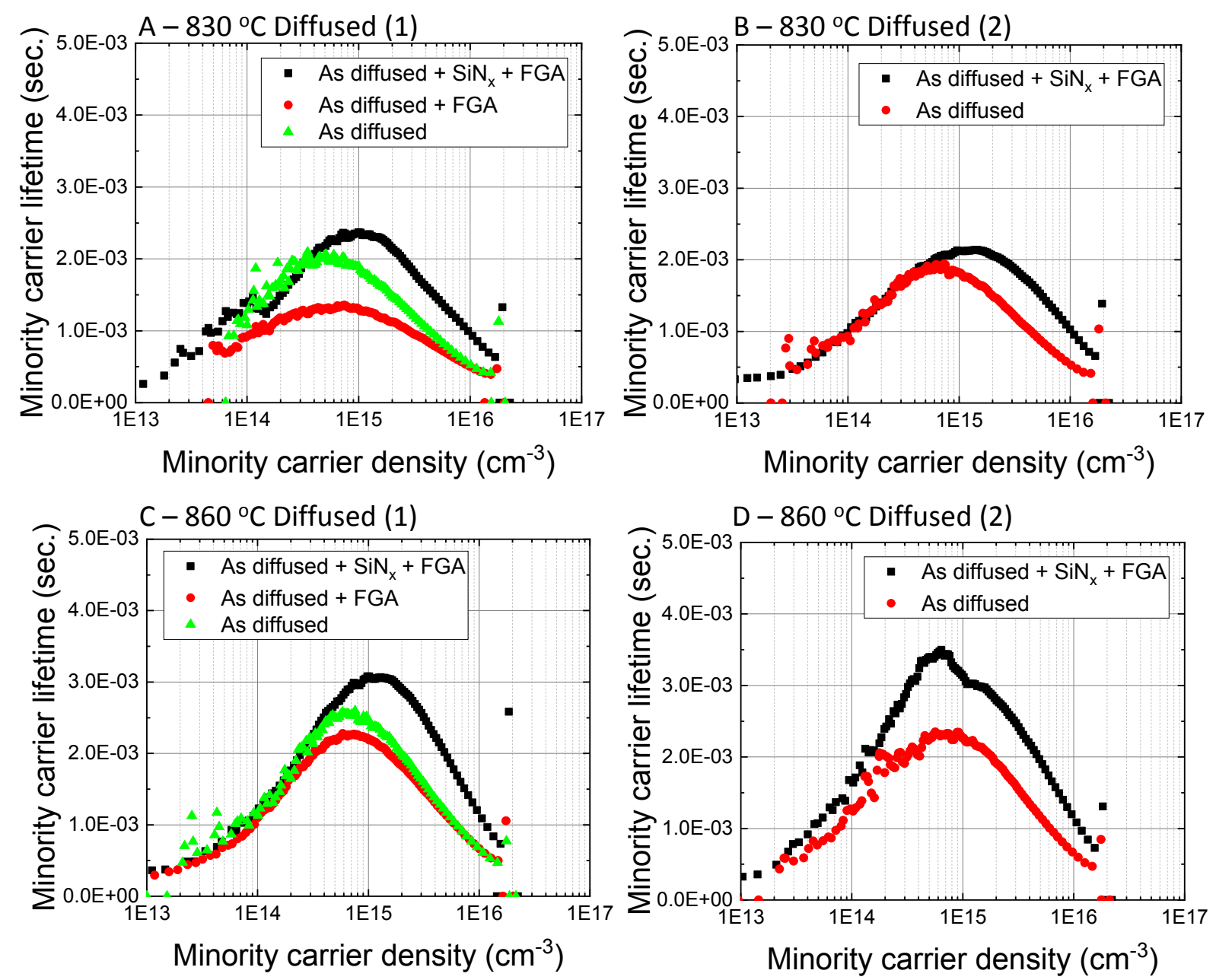

Figure S2. Injection dependence $\tau_{\text {eff }}$ curves of $830^{\circ} \mathrm{C}$ and $860^{\circ} \mathrm{C}$ phosphorus doped poly$\mathrm{Si} / \mathrm{SiO}_{\mathrm{x}} / \mathrm{c}-\mathrm{Si}$ samples at different experiment stages: As diffused, FGA, and $\mathrm{SiN}_{\mathrm{x}}: \mathrm{H}+\mathrm{FGA}$. 

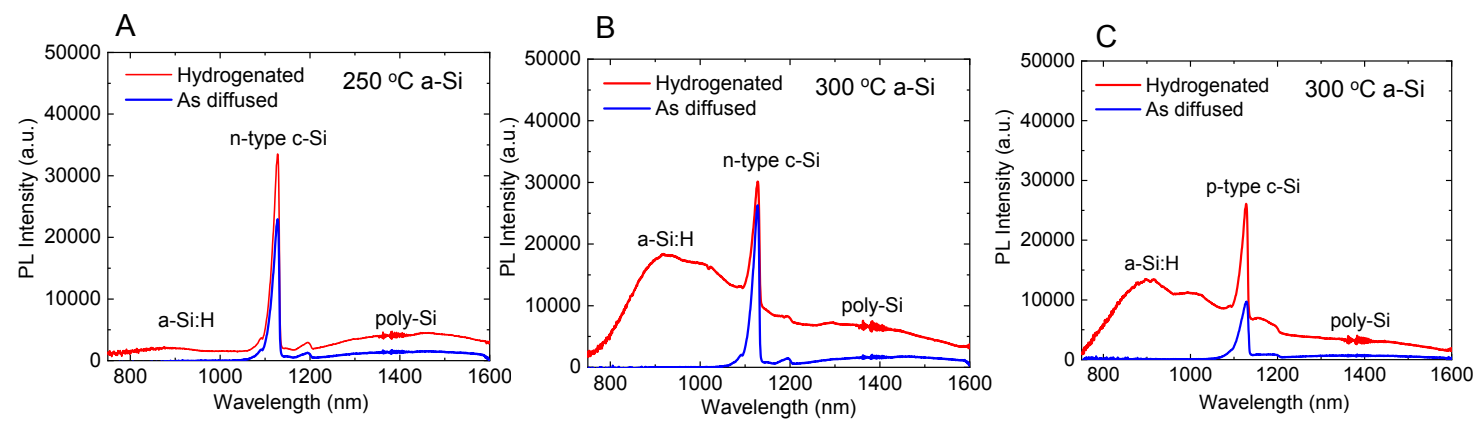

Figure S3. Photoluminescence spectra captured from planar phosphorus-doped poly$\mathrm{Si} / \mathrm{SiO}_{\mathrm{x}} / \mathrm{c}-\mathrm{Si}$ samples with different initial PECVD a-Si:H deposition temperatures and silicon substrate types. The PL spectra were captured at $80 \mathrm{~K}$ using the $405-\mathrm{nm}$ excitation laser. The diffusion temperature was $830^{\circ} \mathrm{C}$. 


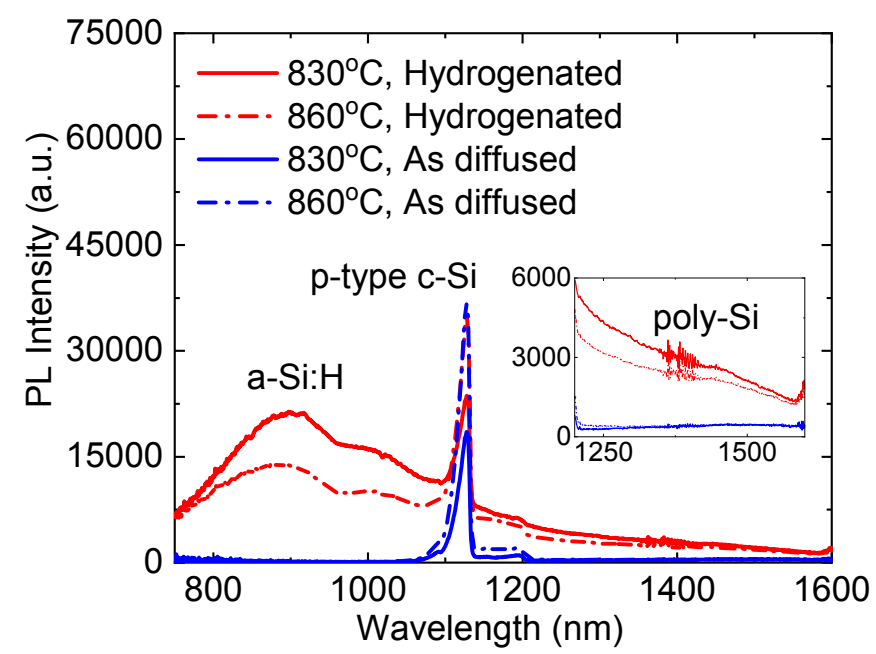

Figure S4. Photoluminescence spectra captured from planar boron-doped poly-Si $/ \mathrm{SiO}_{x} / \mathrm{c}-$ Si samples at different diffusion temperatures on p-type substrates. The PL spectra were captured at $80 \mathrm{~K}$ using the $405-\mathrm{nm}$ excitation laser. The initial PECVD a-Si:H film was deposited at a substrate temperature of $300{ }^{\circ} \mathrm{C}$. 


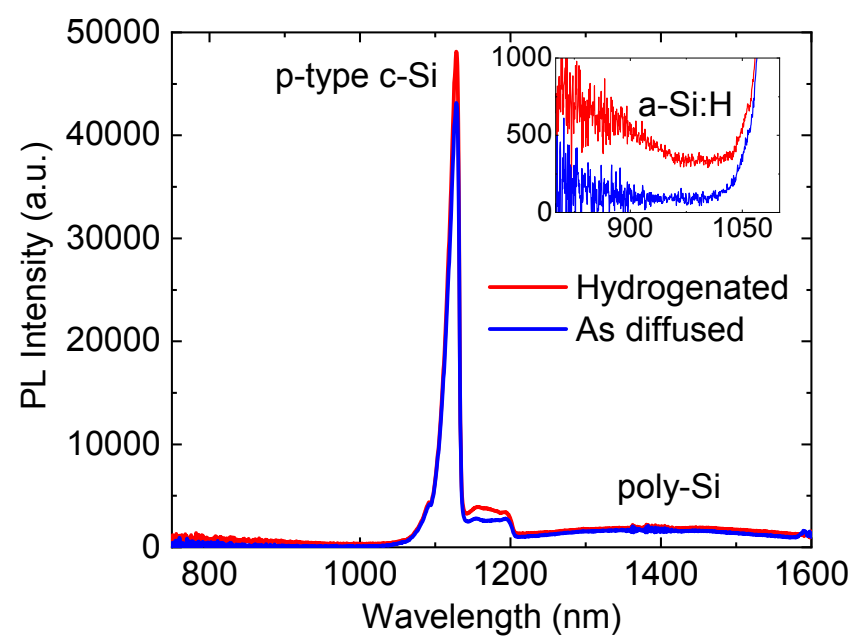

Figure S5. PL spectra from $830{ }^{\circ} \mathrm{C}$ phosphorus-diffused poly-Si/SiO $/ \mathrm{c}-\mathrm{Si}$ samples on $\mathrm{p}$ type textured substrates before and after hydrogenation. The PL spectra were captured at $80 \mathrm{~K}$ using the excitation laser of $405 \mathrm{~nm}$. 